\title{
Throat Spray, Sedation or Anaesthetic?
}

\author{
Anthony T.R. Axon \\ Honorary Professor of Gastroenterology, University of Leeds, Leeds, UK
}

\section{Key Words \\ Digestive endoscopy · Sedation · Unsedated colonoscopy}

\begin{abstract}
Digestive endoscopy covers a wide variety of procedures; the need for sedation is governed by the invasiveness and length of the procedure, the wishes of the patient, the desire of the operator for a compliant patient, and safety. Many patients are prepared to undergo upper digestive endoscopy using throat spray without sedation, while fewer accept unsedated colonoscopy. There are clinical advantages as well as disadvantages in employing sedation and sometimes general anaesthesia is the preferred option. This paper provides an introduction to the choices available and the approaches that are employed in endoscopic sedation practice.

Copyright $\odot 2010$ S. Karger AG, Basel
\end{abstract}

\section{Level of Sedation}

Sedation is delivered at different levels. 'Minimal' sedation (anxiolysis) usually involves an intravenous benzodiazepine, such as midazolam, at a low dosage leaving the patient conscious and able to respond to verbal instructions. 'Moderate' (conscious sedation) requires a larger dose of benzodiazepine or the addition of an opiate, and the patient can respond to purposeful verbal or tactile

\section{KARGER}

Fax +4161306 1234

E-Mail karger@karger.ch

www.karger.com
(C) 2010 S. Karger AG, Basel

0012-2823/10/0822-0077\$26.00/0

Accessible online at: www.karger.com/dig stimuli. 'Deep' sedation involves a large dose of midazolam and opiate such that repeated or painful stimulation is required to evoke a purposeful response [1]. General anaesthesia implies that the patient is unarousable by painful stimuli. The recent introduction of the short-acting anaesthetic propofol can be used in restricted dosage as a sedative and is increasingly popular for endoscopy in many countries. This paper provides an overview of the choices available and the indications for their use.

\section{Choice of Sedation}

The grading of the depth of sedation set out above is referred to as the 'continuum of sedation' [1], but it is not always possible to predict how potent a given dose of sedative will be in every individual. The age, lean body mass, psychological profile and concomitant prescription medications, recreational drugs or alcohol intake may affect the patient's response; therefore, the level of sedation achieved does not necessarily reflect the dose or the nature of the medication chosen, and there is a risk that deeper sedation may inadvertently be reached and cause cardiorespiratory compromise.

The choice of sedation in endoscopy varies widely between endoscopists and throughout the world. In general, deeper sedation is used more in the USA than in Europe (with the exception of France where general anaesthesia is usually employed for most procedures). Certain Scan- 
dinavian endoscopists routinely perform colonoscopy without sedation and many European countries do not provide sedation for upper digestive endoscopy. Concerns relating to oversedation have led the UK to recommend a reduction in dosage to an average of $5 \mathrm{mg}$ of midazolam in average patients and 1-2 mg in the elderly [2].

\section{Cost of Sedation}

Sedation increases the cost of endoscopy. More staff is needed for monitoring during and after the procedure, drugs and disposables must be paid for, the patient is retained in hospital until recovery is satisfactory, an escort home is required, and the patient is unable to go to work. The small risks associated with sedation are also avoided. There are clear advantages both in cost and convenience for both provider and patient to forego sedation in selected cases [3].

\section{Sedation or Not?}

There are, however, significant advantages in providing sedation. Those who find the procedure seriously unpleasant may not only refuse future examinations but spread concern to others. This is particularly important today in view of the increasing role of endoscopy in screening. Unsedated OGD (oesophago-gastroduodenoscopy) is effective in selected patients, but provides reduced operator satisfaction. A meta-analysis showed sedation to achieve better patient cooperation and satisfaction and a willingness to have it repeated [4]. Unsedated colonoscopy is less frequently undertaken, patients are less likely to agree to it [5] or have it repeated. Thirty-five percent of American patients were prepared to undergo unsedated colonoscopy when approached by an experienced endoscopist [6], but only $12 \%$ of American endoscopists would themselves opt for unsedated colonoscopy; of the remainder, over $50 \%$ would prefer propofol [7]. procedures. ERCP, endoscopic submucosal resection, endoscopic ultrasound with biopsy, enteroscopy and treatment of pancreatic cysts are time-consuming, often uncomfortable and require a stable operating field. For this reason, many endoscopists prefer general anaesthesia;

however, few studies have provided data that help with decision-making in this area [1].

Anaesthetic assistance has been recommended in patients where there is an airway risk such as sleep apnoea and certain head and neck deformities, in those likely to be uncooperative, on drugs or alcoholic, and in patients whose ASA grading is IV or V $[7,8]$.

\section{Does Local Anaesthetic Throat Spray Help in Upper Digestive Endoscopy?}

Intubation techniques in upper digestive endoscopy have changed. Slimmer pan-endoscopes and video equipment as opposed to fibreoptic equipment enables intubation to be performed under direct vision. This is less traumatic than the old technique of blind intubation, but requires an absent cough reflex if the larynx is to be viewed easily. Pharyngeal anaesthesia enables endoscopy to be accomplished more easily [9-11]. This applies to sedated as well as unsedated patients according to a recent metaanalysis [12].

Serious allergic reactions were considered to be a risk of local anaesthesia in earlier publications, but these are extremely rare. There is greater concern about the risk of overdosing, and lignocaine (the most commonly used product) is a respiratory depressant and overdosage may cause hypotension, bradycardia and even cardiac arrest [13]. As the spray is rapidly absorbed by mucous membranes [14], the dose should be limited to $200 \mathrm{mg}$ in adults (20 sprays), and in children the limit is 10 sprays. Benzocaine should not be used because it may cause methaemoglobinaemia in susceptible individuals. Patients who have received pharyngeal anaesthesia are at greater risk of aspiration and post-procedure pneumonia $[15,16]$. For this reason, they must avoid oral intake until they have recovered their pharyngeal sensation and the throat spray should be avoided in the elderly who are at greatest risk of this complication.

\section{Sedation or General Anaesthesia?}

Endoscopy is increasingly employed for interventional

References

78
1 Standards of Practice Committee of the American Society for Gastrointestinal Endoscopy, Lichtenstein DR, Jagannath S, Baron TH, Anderson MA, Banerjee S, Dominitz JA, Fanelli RD, Gan SI, Harrison ME, Ikenberry SO, Shen B, Stewart L, Khan K, Vargo JJ: Sedation and anesthesia in GI endoscopy. Gastrointest Endosc 2008;68:815-825.

2 Safety and sedation during endoscopic procedures. http://www.bsg.org.uk/images/stories/docs/clinical/guidelines/endoscopy/sedation.doc. 
3 Abraham NS, Fallone CA, Mayrand S, Huang J, Wieczorek P, Barkun AN: Sedation versus no sedation in the performance of diagnostic upper gastrointestinal endoscopy: a Canadian randomized controlled cost-outcome study. Am J Gastroenterol 2004;99: 1692-1699.

-4 McQuaid KR, Laine L: A systematic review and meta-analysis of randomized, controlled trials of moderate sedation for routine endoscopic procedures. Gastrointest Endosc 2008;67:910-923.

>5 Yörük G, Aksöz K, Unsal B, Buyraç Z, Buran T, Yazicioğlu N, Yildiz C, Yalçin HC: Colonoscopy without sedation. Turk J Gastroenterol 2003;14:59-63.

-6 Rex DK, Imperiale TF, Portish V: Patients willing to try colonoscopy without sedation: associated clinical factors and results of a randomized controlled trial. Gastrointest Endosc 1999;49:554-559.
7 Cohen LB, Wecsler JS, Gaetano JN, Benson AA, Miller KM, Durkalski V, Aisenberg J: Endoscopic sedation in the United States: results from a nationwide survey. Am J Gastroenterol 2006;101:967-974.

8 Riphaus A, Wehrmann T, Weber B, et al: S3 Guideline: sedation for gastrointestinal endoscopy 2008. Endoscopy 2009;41:787-815.

-9 Campo R, Brullet E, Montserrat A, Calvet X, Rivero E, Brotons C: Topical pharyngeal anaesthesia improves tolerance of upper gastrointestinal endoscopy: a randomized double blind study. Endoscopy 1995;27:659-664

10 Hedenbro JL, Ekelund M, Jansson O, Lindblom A: A randomized double blind placebo-controlled study to evaluate topical anaesthesia of the pharynx in upper gastrointestinal endoscopy. Endoscopy 1992;24: 585-587.
1 Jameson JS, Kapadia SA, Polson RJ, McCarthy PT, Misiewicz JJ: Is oropharyngeal anaesthesia with topical lignocaine useful in upper gastrointestinal endoscopy? Aliment Pharmacol Ther 1992;6:739-744.

12 Evans LT, Saberi S, Kim HM, Elta GH, Schoenfeld P: Pharyngeal anesthesia during sedated EGD. Is 'the spray' beneficial. A meta-analysis and systematic review. Gastrointest Endosc 2006;63:761-766.

13 Quine MA, Bell GD, McCloy RF, Charlton JE, Devlin HB, Hopkins A: Prospective audit of upper gastrointestinal endoscopy in two regions of England: safety, staffing and sedation methods. Gut 1995;36:462-467.

14 Covino BG, Vassallo HG: Local Anesthetics. Mechanism of Action and Clinical Use. New York; Grune and Stratton, 1976, p 99.

15 Prout BJ, Metrewell C: Pulmonary aspiration after fibre-endoscopy of the upper gastrointestinal tract. Brit Med J 1972;36:462-471. 